\title{
WATERING OF DOUBLE-CRESTED CORMORANT CHICKS
}

THIJS KUIKEN, Department of Virology, Erasmus University Rotterdam, Rotterdam, The Netherlands

\section{Introduction}

The Double-crested Cormorant is the most widespread of the six species of cormorants in North America. ${ }^{1}$ In Saskatchewan, breeding colonies of Double-crested Cormorants are present in parts of the boreal forest and the prairies in summer; in winter, this species migrates south, mainly to the Gulf of Mexico. ${ }^{1}$ A well-known aspect of its reproductive behaviour is feeding the young on regurgitated food, whereby the chick inserts its whole head into the mouth of the parent. ${ }^{7}$ (See Figure 1.) A more unusual behaviour, and one that has been described only scantily, is the transfer of water from parent to young, i.e., watering.

As far as I know, watering in Doublecrested Cormorants has been described only by van Tets. ${ }^{6}$ In his study of cormorants on Mandarte Island, B.C., van Tets describes how Doublecrested Cormorant chicks beg for water on hot dry days by waving the wide open bill upwards, in contrast to begging for food, which is done with the bill closed. In response, the parent descends to the sea, fills its gullet with water, immediately returns to the nest, and pours water down the throats of its chicks. According to Johnsgard's extensive review of cormorants, darters, and pelicans, similar behaviour occurs in Long-tailed Cormorants, Great Cormorants, Japanese Cormorants and Darters. ${ }^{3}$ Here I provide further details on this behaviour in Double-crested Cormorants observed at a breeding colony in Saskatchewan.

\section{Materials and Methods}

A mixed breeding colony of Doublecrested Cormorants and American White Pelicans on Island A, Doré Lake, Saskatchewan (54 $46^{\prime} \mathrm{N}, 107^{\circ} 17^{\prime} \mathrm{W}$ ) was studied each summer from 1994 to 1996. Observations were made every three days from the beginning of June, before any eggs had hatched, to the end of August, when most young had fledged, from within an 88-m-long tunnel-and-blind system to minimize disturbance to the birds. About 500 cormorant nests were visible from inside this system. The main objective of this study was to learn more about Newcastle disease and other causes of mortality in Double-crested Cormorants. ${ }^{4}$ However, observations on the birds' behaviour also were recorded.

\section{Results}

Cormorants were seen watering twoto four-week-old chicks during warm (about $25^{\circ}$ to $30^{\circ} \mathrm{C}$ ) sunny periods, usually when there was no wind or a light wind. This behaviour was seen between about $1130 \mathrm{~h}$ and $1630 \mathrm{~h}$ on 23 and 28 July $1994 ; 20$ July $1995 ; 11,15,19,22$, 29 July and 1 August 1996. On these days, the number of nests at which this behaviour was seen ranged from one to at least 20. During the periods when watering behaviour was seen, many cormorants and pelicans also showed gular fluttering.

Typically, a chick would face the attending adult (the behaviour was seen only when a single adult was attending the nest) and open its mouth wide (about $45^{\circ}$ to $50^{\circ}$ ), with mandibles bowed 


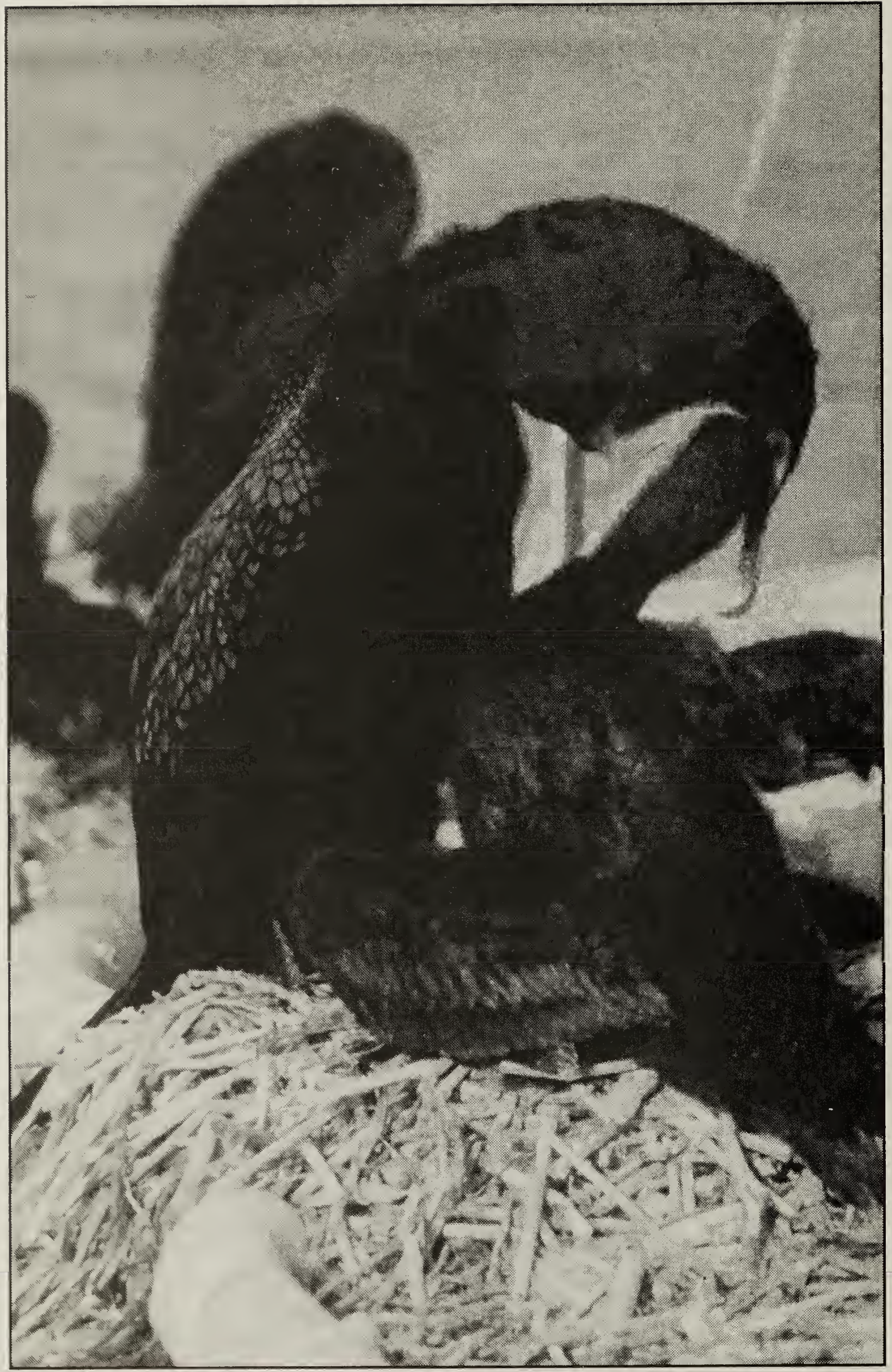

Figure 1. Adult Double-crested Cormorant feeding a chick. Note that the head of the chick is inserted into the adult's mouth.

Thijs Kuiken 


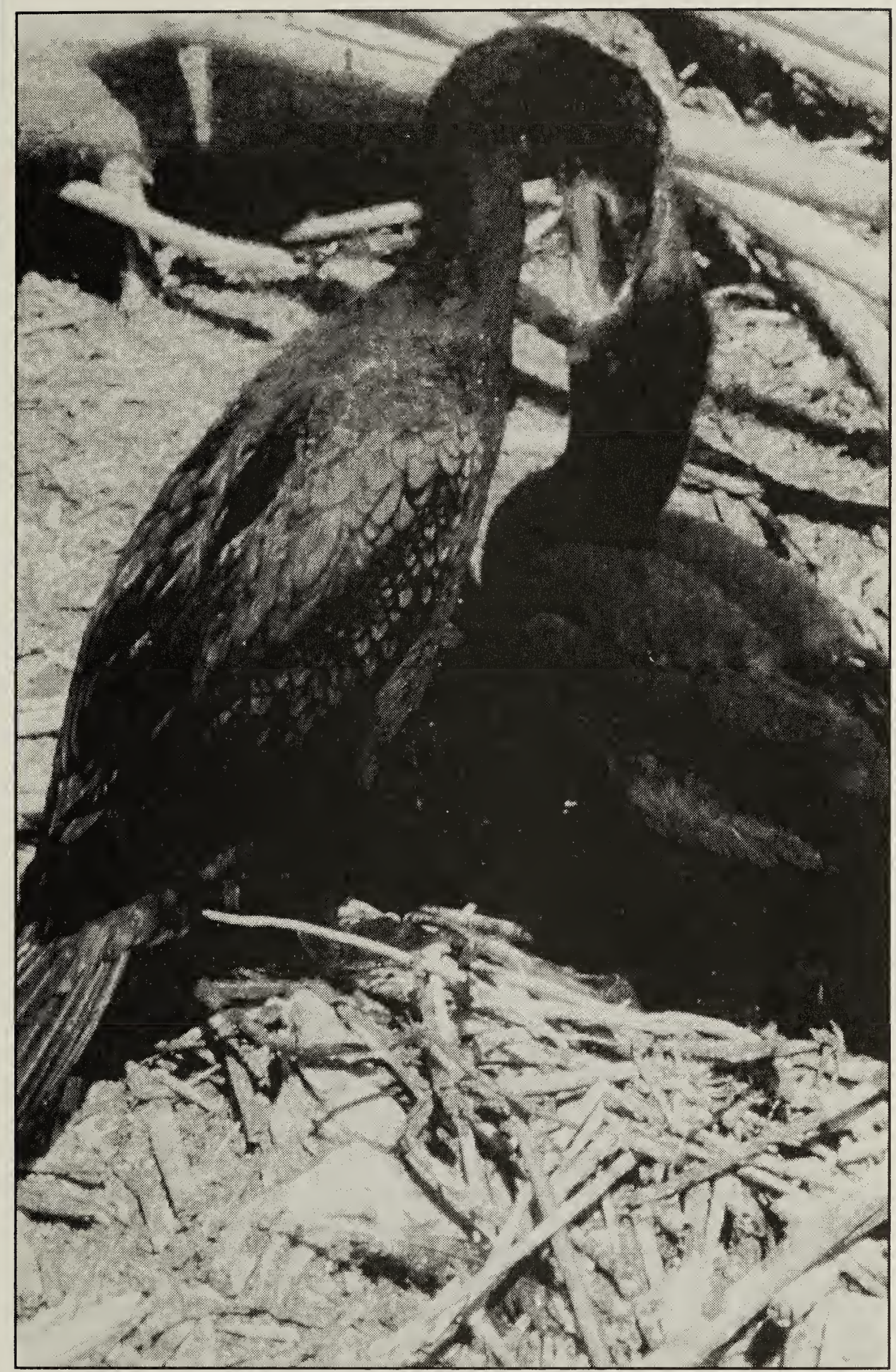

Figure 2. Adult Double-crested Cormorant watering a chick. Note that the head of the adult is inserted in the chick's mouth, which is wide open.

Thijs Kuiken 
outward convexly and gular pouch distended. The head and wings were held still, with the wings close to the body. The chick made a sound similar to the threat call, with all component sounds made on exhalation: eh - oh $a h-a-a-a-a-a$.

This behaviour differed distinctly from begging for food observed at the colony, where the chick kept its mouth closed, wove its head and neck from left to right, and flapped its wings. The food-begging sound also was different, similar to a wheezing donkey's bray, with the "eeh" made on inhalation, and the "uuh" on exhalation: eeh - uuh - eeh - uuh.

In response to this behaviour - and occasionally, in the absence of any visible water-begging behaviour from the chick - the adult attending the chick flew from the nest and landed in the water close to shore. It immediately started swallowing water by dipping its head under water with mouth partly open $\left(30^{\circ}\right)$ and gular pouch depressed. This head-dipping was repeated several times, up to a maximum of 13 . Within a minute of landing in the water, the cormorant returned to the nest, either flying, walking, or a combination of both. It had a 3 to $5 \mathrm{~cm}$ diameter round bulge at the base of the neck and to the right of the median line. If the cormorant bumped against a branch on the way back to the nest, water spilled out of its mouth.

Back at the nest, the adult usually stood on a branch about 5 to $10 \mathrm{~cm}$ higher than the nest containing the chick. The chick started begging for water again, and the adult held its body and the lower part of its neck at a $45^{\circ}$ angle relative to the horizon, sharply flexed the middle part of its neck, and pointed the upper part of its neck and its head downwards at a $45^{\circ}$ to $90^{\circ}$ angle. Occasionally the adult stood at the same level as the chick and then had to hold its body nearly vertically to be able to reach the chick's mouth. The adult put its head into the chick's mouth, up to the point where the adult's eye was level with the chick's mouth corner, allowed water to pour in for about 1 to 10 seconds, and then extracted its head (Figure 2). During this process, the adult's mouth was opened about $5^{\circ}$ to $30^{\circ}$, and the chick's about $45^{\circ}$ to $50^{\circ}$. The adult repeated this process up to 20 times in rapid succession, with the same chick or alternating with other water-begging chicks in the nest. After the adult stopped watering, it either started preening or returned to the lake to collect more water. One adult was seen collecting water three times for its chicks. After the water-begging chick received water, it either continued to beg for water, started to beg for food or stopped begging altogether.

\section{Discussion}

Watering behaviour was observed only on warm sunny days, when cormorant chicks showed abundant gular fluttering, an important cooling mechanism which acts through evaporation of water from the inner surface of the gular pouch. ${ }^{5}$ Adult cormorants likely water their chicks to compensate for this extra loss of water.

The observations of parental care of both pelicans and cormorants at the same colony site raise the question of why cormorants watered their chicks, while pelicans did not. A possible explanation is that cormorant chicks have black plumage and thus absorb more energy from sunlight than pelican chicks, which have white plumage. With similar exposure to the sun, cormorant chicks require more gular fluttering than pelican chicks to keep their bodies cool and therefore lose more water through evaporation. 
Adult cormorants carrying water had a visible bulge at the base of the neck at a location corresponding to that of the esophagus. Because Double-crested Cormorants have a highly expandible esophagus directly connected to a thin sac-like stomach, they probably carry water both in stomach and esophagus. ${ }^{3}$

The age of chicks being watered ranged from about two to four weeks. Beyond this age, chicks of groundnesting Double-crested Cormorants start to leave their nest and would be able to obtain water independently. ${ }^{2}$ The reason why watering was not seen in chicks younger than two weeks of age, despite the same intensity of observations, is not clear. Perhaps younger chicks are better protected from the sun by the shade of their parents and therefore do not lose as much water through gular fluttering.

\section{Acknowledgments}

Thanks to lan Shirley for preparing the photographs in this article.

1. Hatch, J. J. 1995. Changing populations of Double-crested Cormorants. Colonial Waterbirds 18 (Special Publication 1): 8-24.

2. Lewis, H. F. 1929. The Natural History of the Double-crested Cormorant
(Phalacrocorax auritus auritus (Lesson)). Ph.D. Thesis, Cornell University, Ithaca, New York, 94 pp.

3. Johnsgard, P. A. 1993. Cormorants, Darters, and Pelicans of the World. Smithsonian Institution Press, Washington, D.C., 445 pp.

4. Kuiken, T., F. A. Leighton, G. Wobeser, and B. Wagner. 1999. Causes of morbidity and mortality and their effect on reproductive success in Doublecrested Cormorants from Saskatchewan. Journal of Wildlife Diseases 35: 331-346.

5: Lasiewski, R. C., and G. K. Snyder. 1969. Responses to high temperature in nestling Double-crested and Pelagic cormorants. Auk 86: 529-540.

6. Van Tets, G. F. 1959. A Comparative Study of the Reproductive Behaviour and Natural History of Three Sympatric Species of Cormorants, (Phalacrocorax auritus, P. penicillatus, \& P. pelagicus) at Mandarte Island, B.C. M. A. Thesis, University of British Columbia, Vancouver, British Columbia, 86 pp.

7. Van Tets, G. F. 1965. A comparative study of some social communication patterns in the Pelecaniformes. Ornithological Monographs 2: 1-88.

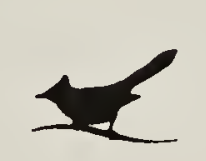

The spectacular shifting sands [of the Lake Athabasca Sand Dunes ] constitute the largest active dune environment in Canada, as well as one of the largest in the world north of 59 degrees latitude. Spread over a belt of some 1,500 square kilometres, largely between the major north-flowing rivers - MacFarlane River on the east, Dumville Creek and William River on the west - the extent of the dunes is such that from a distance, on cloudy days, they project on the sky a strange coppery glow. "

Stan Rowe, Home Place p. 97 